\title{
Disposition and Biocompatibility of Dextrin-coated Cadmium Sulphide Nanoparticles after a Single Dose and Multiple Doses in Rats
}

\author{
GERARDO GONZALEZ DE LA CRUZ, ROCÍO GÓMEZ-CANSINO'1, PATRICIA RODRÍGUEZ-FRAGOSO, PAOLA JAIMES- \\ CHÁVEZ ${ }^{1}$, ANA L. BARBOSA-RAYO' ${ }^{1}$, JORGE REYES-ESPARZA ${ }^{1}$, LOURDES RODRÍGUEZ-FRAGOSO ${ }^{1 *}$ \\ Departamento de Física, CINVESTAV - I.P.N. Apartado Postal 14-740, 07000. Mexico, D.F., Mexico, ${ }^{1}$ Facultad de Farmacia, \\ Universidad Autónoma del Estado de Morelos, Cuernavaca 62210, Mexico
}

González et al.: Disposition and Biocompatibility of Dextrin-coated Cadmium Sulphide Nanoparticles

\begin{abstract}
To investigate nanoparticles disposition and elimination, dextrin-coated cadmium sulphide nanoparticles were administered intraperitoneally as a single or multiple doses to rats. Nanoparticles distribution in liver, kidney, heart, lung, muscle, testis, brain, spleen and thymus was investigated up to $90 \mathrm{~d}$ after daily administration for 30,60 and $90 \mathrm{~d}$. Tissue distribution was measured in homogenates as fluorescence intensity by spectrophotometry. Tissue concentrations with time for dextrin-coated cadmium sulphide nanoparticles were plotted and some pharmacokinetics parameters were obtained. Serum biochemical parameters were determined using spectrophotometry. Nanoparticles in tissue samples were visualised under an epifluorescence microscope and histological analysis was also performed. After a single administration in rats, nanoparticles were distributed quickly with a $\mathrm{C}_{\max }$ occurring in the first 72 hours in all tissues analysed. The elimination $\mathbf{t}^{1 / 2}$ of nanoparticles was less than 12 days in kidney, spleen, lung and brain; however, it was more than 40 days in muscle, liver and testicle with a mean residence time greater than 50 days. Alterations in glucose, triglycerides and alkaline phosphatase, were observed since the first day and continued throughout the 90 days post dose. Biocompatibility study showed that dextrin-coated cadmium sulphide nanoparticles only produced degenerative alterations in testis and chronic inflammation in lungs after continuous administration during the 90 days. In conclusion, dextrin-coated cadmium sulphide nanoparticles are widely distributed in tissues and have a very long residence time without producing significant toxicity. The multi-dose study showed that these produce selective toxicity after administration for long periods of time. These characteristics make the dextrin-coated cadmium sulphide nanoparticles ideal for theranostic purposes.
\end{abstract}

Key words: Disposition, biocompatibility, nanoparticles, pharmacokinetic

The development of nanomaterials has increased dramatically during the past decade ${ }^{[1]}$. However, currently only very few studies focus on the disposition of nanomaterials in vivo as well as the time taken to completely eliminate them in the organisms ${ }^{[2,3]}$. Researchers intended to study nanomaterial biocompatibility need to understand what happens to these after administered to living organisms. Predicting disposition of a nanomaterial is very important in the process of developing new nanomaterials for theranostic use in human beings ${ }^{[4]}$. All preclinical studies on nanomaterials should require a pharmacokinetic study in order to predict and understand the disposition once the nanomaterial enters the organism, when it is finally completely eliminated, and how safe its use is overall. The fate and disposition

*Address for correspondence E-mail: mrodriguezf@uaem.mx

September-October 2019 of any nanomaterial should be based on its properties, site of administration, formulation, and dosage ${ }^{[5]}$. For this reason, it is necessary to explore biocompatibility, tolerance and characterize the pharmacokinetic profile of each synthetized nanomaterial.

An important parameter to consider in pharmacokinetic studies is the estimated mean time a drug resides in the body within specific tissues; the mean residence time (MRT) can help assess the extent of its efficacy and

This is an open access article distributed under the terms of the Creative Commons Attribution-NonCommercial-ShareAlike 3.0 License, which allows others to remix, tweak, and build upon the work non-commercially, as long as the author is credited and the new creations are licensed under the identical terms

Accepted 05 August 2019

Revised 14 May 2019

Received 11 January 2019

Indian J Pharm Sci 2019;81(5):876-884 
tolerability ${ }^{[6]}$. For nanomaterials, this parameter is also quite essential because the residence time specifies how long it stays in the organism and the estimated time period during which it might identify a pathogenic microorganism, tumor cells or molecular markers for diagnostic purposes, as well as for delivering drugs or genes in therapeutic treatments. Several studies have demonstrated that nanomaterials are delivered to several organs and that these even cross biological barriers ${ }^{[7-10]}$. In addition to this, these have selectivity for specific tissues and remain within for long periods of time, which are ideal properties if they are used to carry drugs, antibodies or vaccines. Few studies reported analysis of nanoparticle disposition and how long these remained inside the tissues before completely eliminated after a single dose administration ${ }^{[1]}$.

These past few years, our group has synthesized and carried out in vitro and in vivo studies of cadmium sulphide nanoparticles coated with sugar polymers, and found that these were biocompatible and well tolerated in rodents ${ }^{[12,13]}$. Our in vitro studies showed dextrincoated cadmium sulphide (CS-DX) nanoparticles were efficiently delivered at the cellular and subcellular levels ${ }^{[14]}$; additional studies have confirmed effective tissue distribution and safety in rodents after multiple administrations over a short period of time. Given the great tolerability observed in previous studies using experimental animals, those findings suggested that nanoparticles would be rapidly eliminated without producing any biochemical alterations.

The characteristics that have been shown to have the CS-DX nanoparticles suggest that they have the potential to be used for imaging for research and clinical purposes. However, in order to use them with this last purpose it is necessary to know their disposition and their elimination time and also to identify their side effects after multiple doses. Therefore, the present study had two goals. First goal was to characterize CS-DX nanoparticles' disposition after a single dose administered to rats and detailed analysis of a series of pharmacokinetic parameters, such as the $\mathrm{C}_{\max }, \mathrm{T}_{\max }$, $\mathrm{AUC}_{0-\mathrm{t}}, \mathrm{AUC}_{0-\infty}, \mathrm{K}_{\mathrm{e}}$ and MRT, along with biochemical parameters while nanoparticles remained in the rats. Rats were observed for a period of $90 \mathrm{~d}$ after a single dose administration in order to investigate when these were completely eliminated. The second goal was to address the biocompatibility of CS-DX nanoparticles after daily administration for 30, 60 and $90 \mathrm{~d}$. Biochemical parameters and morphology of certain tissues were studied.

\section{MATERIAL AND METHODS}

All chemicals for the preparation of nanomaterial were purchased from Sigma-Aldrich unless otherwise stated. Commercial diagnostic kits to estimate alanine aminotransferase (ALT), aspartate aminotransferase (AST), alkaline phosphatase (ALP), glucose, cholesterol and triglycerides (TG), urea, creatinine and uric acid were purchased from ELITech, Mexico. Male Wistar rats weighing 110-130 g were obtained by Envigo S.A. (Mexico). All rats were kept in a controlled environment and allowed food (Standard Purina Chow Diet, Mexico) and water ad libitum. The rats were fasted for $12 \mathrm{~h}$ prior to treatment. Experimental protocols were designed in accordance with the International Guides for practice in animals ${ }^{[15]}$.

\section{CS-DX nanoparticles:}

Cadmium sulphide nanoparticles using dextrin as a capping agent was prepared according to the process described previously ${ }^{[13]}$. Briefly, cadmium sulphide nanoparticles were prepared in aqueous solution. $0.02 \mathrm{M}$

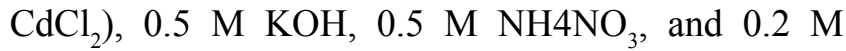
$\mathrm{CS}\left(\mathrm{NH}_{2}\right)_{2}$ were added and the mixture was stirred and heated at $80^{\circ}$. Similar conditions were applied to dextrin with $3 \%$ concentration at $\mathrm{pH} 11$. The solution immediately turned a light yellow color, indicating the initial formation of a CS nanoparticle. The temperature of the mixture was kept at $75^{\circ}$ and maintained at this temperature for $60 \mathrm{~min}$. The nanoparticles were separated by centrifugation at $6000 \mathrm{rpm}$ during $60 \mathrm{~min}$, and deposited in solid form from the solution; finally, they were washed several times with deionized water and dried at $40^{\circ}$ for $24 \mathrm{~h}$.

\section{CS-DX nanoparticle disposition analysis:}

Rats were randomly divided into two groups, control group $(\mathrm{n}=5)$ animals were treated with a single ip dose of phosphate buffered saline (PBS, $200 \mu \mathrm{l})$ and the CSDX nanoparticle group $(n=65)$ was treated with a single ip dose of $100 \mu \mathrm{g} / \mathrm{kg}$ CS-DX nanoparticles prepared in $200 \mu \mathrm{l}$ of PBS. Animals were sacrificed 3, 6, 12, 18, 24, $48,72,150,300,600,960,1440$ and $2160 \mathrm{~h}(90 \mathrm{~d})$ after administration. Five animals were used per time point. A post-mortem macroscopic examination was carried out to search for macroscopic alterations. Tissues were collected and preserved in $10 \%$ neutral-buffered formalin fixative after time samples were processed for a histopathological inspection. Serum samples were also obtained and maintained at $-75^{\circ}$ for biochemical analysis. Nanoparticle disposition and pharmacokinetic 
analysis employed fluorescence quantitative analysis. Liver, kidney, lung, heart, striated muscle, spleen, thymus, brain, and testis were examined. Tissues $(50 \mathrm{mg})$ were homogenized with lysis buffer (20 mM HEPES, $2 \mathrm{mM}$ EGTA, $50 \mathrm{mM} \beta$-glycerol phosphate, $5 \mathrm{mM}$ sodium fluoride, $50 \mu \mathrm{M}$ DTT, $100 \mathrm{mM}$ PMSF). The fluorescence was quantified by spectrophotometry (Perkin Elmer) using the excitation wavelength of $485 \mathrm{~nm}$.

Tissues were treated as mentioned above, but samples were not stained and tissues were rinsed with $1 \mathrm{mg} / \mathrm{ml}$ solution of sodium borohydride as a blocking agent to reduce autofluorescence. To obtain clear images regarding the disposition of nanoparticles, unstained tissue samples were analysed under an epifluorescence microscope. The amount of nanoparticles was estimated by measuring fluorescence intensity by spectrophotometry in tissue homogenates; the intensity of fluorescence was expressed as arbitrary units (AU). Individual tissue concentration-versus actual time curves were built to derive non-compartmental pharmacokinetic parameters. The pharmacokinetic parameters obtained included, $\mathrm{C}_{\max }, \mathrm{T}_{\max }, \mathrm{AUC}_{0-\mathrm{t}}$, $\mathrm{AUC}_{0-\infty}, \mathrm{T}_{1 / 2}, \mathrm{Ke}$ and MRT, according the next Eqns. ${ }^{[16,17]}, \mathrm{K}_{\mathrm{e}}=-\left(\operatorname{lnC}_{1}-\operatorname{lnC}_{0}\right) / \mathrm{t} ; \mathrm{AUC}_{0-\mathrm{t}}=\mathrm{AUC}_{0}^{\mathrm{t}}=$ $\mathrm{C}_{0}+\mathrm{C}_{1} / 2\left(\mathrm{t}_{1}-\mathrm{t}_{0}\right)+\mathrm{C}_{1}+\mathrm{C}_{2} / 2\left(\mathrm{t}_{2}-\mathrm{t}_{1}\right)+\ldots \mathrm{C}_{\mathrm{n}-1}+\mathrm{C}_{\mathrm{n}} / 2\left(\mathrm{t}_{\mathrm{n}}-\mathrm{t}_{\mathrm{n}-1}\right) \mathrm{K}$; $\mathrm{AUC}_{0}{ }^{\infty}=\mathrm{C}_{\mathrm{f}} / \mathrm{K}_{\mathrm{e}} ; \mathrm{MRT}=\mathrm{AUMC}_{0}{ }^{\infty} / \mathrm{AUC}_{0}{ }^{\infty}$.

Maximal concentration $\left(\mathrm{C}_{\max }\right)$ was considered as maximal concentration achieved by CS-DX. Time of maximum concentration $\left(\mathrm{T}_{\max }\right)$ was considered as the time at which $\mathrm{C}_{\max }$ was achieved by CS-DX nanoparticles. The analysis of biochemical parameters was performed using colorimetric methods. The study included glucose, triglyceride, cholesterol, AST, ALT, PA, urea, creatinine and uric acid level quantitation using commercial kits and following manufacturer protocols.

\section{Biocompatibility of CS-DX nanoparticles in rats:}

Twenty four male Wistar rats weighing 110-130 g were assigned to one of four groups: (1) control group rats (6 animals) were treated daily with an ip dose of PBS $(200 \mu \mathrm{l})$ for $90 \mathrm{~d}$; (2) the CS-DX nanoparticle group (18 animals) was treated daily with an ip dose of $100 \mu \mathrm{g} / \mathrm{kg}$ CS-DX nanoparticles during 30, 60 or $90 \mathrm{~d}$. After said periods, the animals were sacrificed as described. Tissue samples were processed and observed under a light as well as epifluorescence microscope to carry out a histopathological analysis. A biochemical analysis of blood samples was also performed.

\section{Statistical analysis:}

The data were expressed as the mean $\pm \mathrm{SD}$ and statistically analysed using the t-test, and ANOVA calculated with the help of the SPSS 10.0 software (SPSS Inc., Chicago, Ill., USA). Differences were considered significant at $\mathrm{p}<0.05$.

\section{RESULTS AND DISCUSSION}

During the study, rodents were closely monitored to ensure they did not suffer side effects from the nanoparticles. Safety assessments consisted of daily observations, body weight and food consumption. A rigorous evaluation was made in order to find out alterations in, motor apparatus (ataxia, tremors, arching, rolling, tonic extension or clonic seizures), central nervous system (anaesthesia, sedation, depression or hypnosis), and physical aspect (lacrimation, exophthalmos, piloerection, salivation or diarrhoea).

Fig. 1 shows the disposition of nanoparticles seen as concentration-time profile and measured as fluorescence intensity (AU) in liver, kidney, heart, lung, spleen, thymus, muscle, brain and testis. The $\mathrm{T}_{\max }$, or observed time to reach the maximum nanoparticle concentration in tissues $\left(\mathrm{C}_{\max }\right)$ was mostly between 1 and 2 (24-48 h), although it remained in muscle at $6.25 \mathrm{~d}(150 \mathrm{~h})$. The profile curve and pharmacokinetic parameters were different for each tissue studied. The $\mathrm{C}_{\max }$ was more intense in liver $(65,739 \mathrm{AU})$ and, consequently, both $\mathrm{AUC}_{0-\mathrm{t}}$ and $\mathrm{AUC}_{0-\infty}$ were higher here than in the other tissues (Table 1), reaching $\mathrm{T}_{\max }$ on $\mathrm{d} 3(72 \mathrm{~h}$ ). Nanoparticle levels remained high in liver for $40 \mathrm{~d}$, gradually decreasing; however, at $90 \mathrm{~d}$, significant levels of fluorescence were still detected. Interestingly, the calculated MRT for liver was of $69 \mathrm{~d}$ with a $t_{1 / 2}=$ $48 \mathrm{~d}$ (elimination half time). The concentration-time profile in lung, kidney, heart, spleen, muscle and thymus was low compared with liver, particularly in thymus $\left(\mathrm{C}_{\max } 7339,6018,3679,4386,2515\right.$ and 573 AUs, respectively). MRT was different for each tissue: kidney $9.3 \mathrm{~d}$; heart $16 \mathrm{~d}$; lung $14.8 \mathrm{~d}$; spleen $10.4 \mathrm{~d}$, and muscle $59 \mathrm{~d}$. The $\mathrm{t}_{1 / 2}$ was below $12 \mathrm{~d}$ in kidney, heart, lung, and spleen (fig. 1 and Table 1); the muscle had an elongated $t_{1 / 2}(41.3 \mathrm{~d})$. Interestingly, we also found nanoparticles in brain and testis. The intensity of fluorescence was low in the brain (6561), with a $\mathrm{MRT}=8.5 \mathrm{~d}$ and $\mathrm{a} \mathrm{t}_{1 / 2}=5.9 \mathrm{~d}$. However, fluorescence intensity was very high in testis (16,810 AUs), with a MRT $=83.3 \mathrm{~d}$ and $t_{1 / 2}=58 \mathrm{~d}$. Fig. 2 shows a representative slice from tissues analysed under light and epifluorescence microscope in stained and non- 


\begin{tabular}{lcccccc}
\hline Tissue & $\mathrm{C}_{\max }(\mathrm{AU})$ & $\mathrm{T}_{\max }(\mathrm{h})$ & $\mathrm{AUC}_{0-\mathrm{t}}\left(\mathrm{AU}{ }^{*} \mathrm{~h}\right)$ & MRT $(\mathrm{d})$ & $\mathrm{T}_{y_{2}}(\mathrm{~d})$ & $\mathrm{K}_{\mathrm{e}}\left(\mathrm{h}^{-1}\right)$ \\
\hline Liver & $65739 \pm 1621$ & 72 & $26484058 \pm 74650$ & $69 \pm 8$ & $48 \pm 6$ & $0.0006 \pm 0.00008$ \\
Kidney & $6018 \pm 1257$ & 24 & $519582 \pm 8348$ & $9.3 \pm 9$ & $6.41 \pm 0.8$ & $0.0045 \pm 0.0009$ \\
Heart & $3679 \pm 552$ & 72 & $3637750 \pm 45823$ & $16.0 \pm 7$ & $11.1 \pm 3$ & $0.0026 \pm 0.0007$ \\
Lung & $7339 \pm 2070$ & 48 & $3794373 \pm 72859$ & $14.8 \pm 6$ & $10.31 \pm 4$ & $0.0028 \pm 0.0006$ \\
Spleen & $4386 \pm 468$ & 48 & $1147335 \pm 93856$ & $10.4 \pm 7$ & $7.04 \pm 2$ & $0.0041 \pm 0.0009$ \\
Brain & $6561 \pm 1427$ & 24 & $1487975 \pm 69784$ & $8.5 \pm 4$ & $5.9 \pm 0.8$ & $0.0049 \pm 0.0005$ \\
Testis & $16810 \pm 5426$ & 48 & $11677942 \pm 79385$ & $83.3 \pm 3$ & $58 \pm 12$ & $0.0005 \pm 0.00001$ \\
Muscle & $2515 \pm 896$ & 150 & $1582380 \pm 99563$ & $59 \pm 8$ & $41.3 \pm 17$ & $0.0007 \pm 0.00002$ \\
\hline
\end{tabular}

Each value represents the average $\pm S D, n=5$

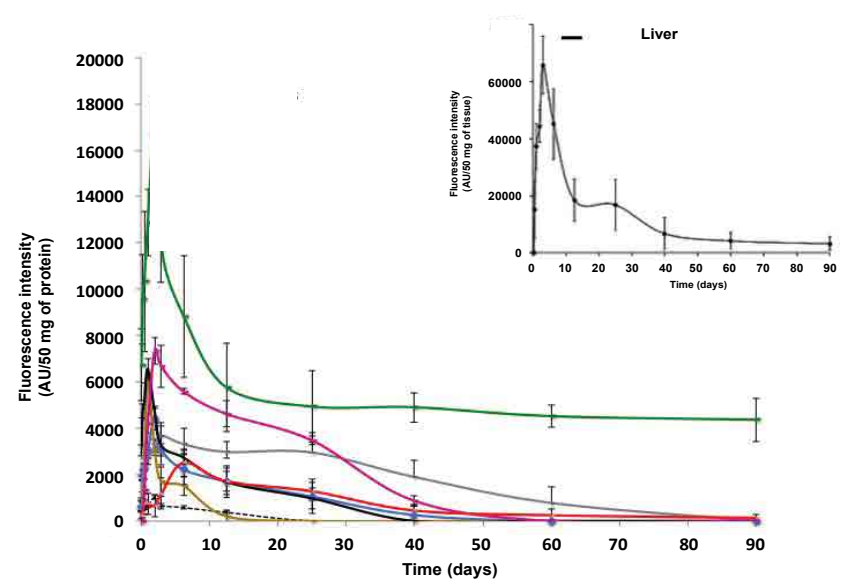

Fig. 1: Single dose time-concentration profiles of CS-DX nanoparticles in tissues in rats

Time-concentration profiles of distribution of CS-DX nanoparticles in tissues over a period of $90 \mathrm{~d}$ after a single intraperitoneal administration to rats. Each point represents the mean \pm SD of 5 animals. (-^) Spleen, (----) thymus, $(\longrightarrow)$ kidney, (-) heart, (-) brain, (-) testis, (-) lung, (-) muscle

stained samples, respectively; microphotographs were taken during the maximum fluorescence time $\left(\mathrm{t}_{\max }\right)$ and at $90 \mathrm{~d}$. CS-DX nanoparticles were identifiable because they emited green colored fluorescence (fig. 2). The fluorescence intensity was different for each tissue. The histopathological analysis revealed morphological alterations in testis due to the presence of nanoparticles. The changes were characterized by a reduction of Leydig cells, changes in interstitial tissue and seminiferous ducts.

The biochemical analysis showed that CS-DX nanoparticles induced changes in almost all analysed parameters. Fig. 3 shows the variations observed throughout the $90 \mathrm{~d}$ of the study, glucose, TG and ALP had important variations. Changes were observed since the first hour until $45 \mathrm{~d}$. However, glucose and ALP subsequently reached normal values by the end of the study (90 d). Triglyceride levels, on the other hand, remained high at $90 \mathrm{~d}$. Slight changes were found in
AST, ALT and urea. No changes were observed in cholesterol, uric acid and creatinine.

Fig. 4 shows representative tissue slices obtained from rats treated daily during 30,60 and $90 \mathrm{~d}$ captured under an epifluorescence microscope. All time periods resulted in a homogeneous distribution of nanoparticles in all analysed tissues. The intensity of fluorescence increased as the treatment time increased. Fig. 5 shows representative slices from tissue stained with $\mathrm{H}$ and $\mathrm{E}$. Images from liver, kidney, and brain did not show any morphological alterations, and tissues are quite similar to control. However, microphotographs from the lung region evidenced the presence of an inflammatory infiltrate after $90 \mathrm{~d}$ of treatment; on the other hand, testis showed atrophy and degenerative changes $90 \mathrm{~d}$ after receiving the CS-DX nanoparticles. Table 2 shows the quantification of biochemical parameters at 30,60 and $90 \mathrm{~d}$. No alterations were found in rats treated daily with CS-DX nanoparticles for $30 \mathrm{~d}$. Animals treated daily with CS-DX nanoparticles for $60 \mathrm{~d}$ showed elevated AP (73\%) and urea (41\%) levels when compared to the control group $(\mathrm{p}<0.05)$. However, only urea levels remained elevated (28\%) after $90 \mathrm{~d}$ of treatment. No changes were observed in either cholesterol or creatinine levels during all time periods.

In pharmacology, disposition indicates the fate of a drug inside the body, it represents the sum of all absorption, distribution, metabolism and excretion (ADME) processes ${ }^{[18]}$. Although nanomaterials are not drugs, these must nevertheless pass through the same ADME processes once administered to the organism. But it could be assumed these processes are more complex given the physical, chemical and optical properties of nanomaterials. MRT on the other hand ${ }^{[6]}$, help understand the effect span for direct-acting molecules. In the case of nanomaterials, the average time nanoparticles reside in the organism or the average time in which they leave it. 


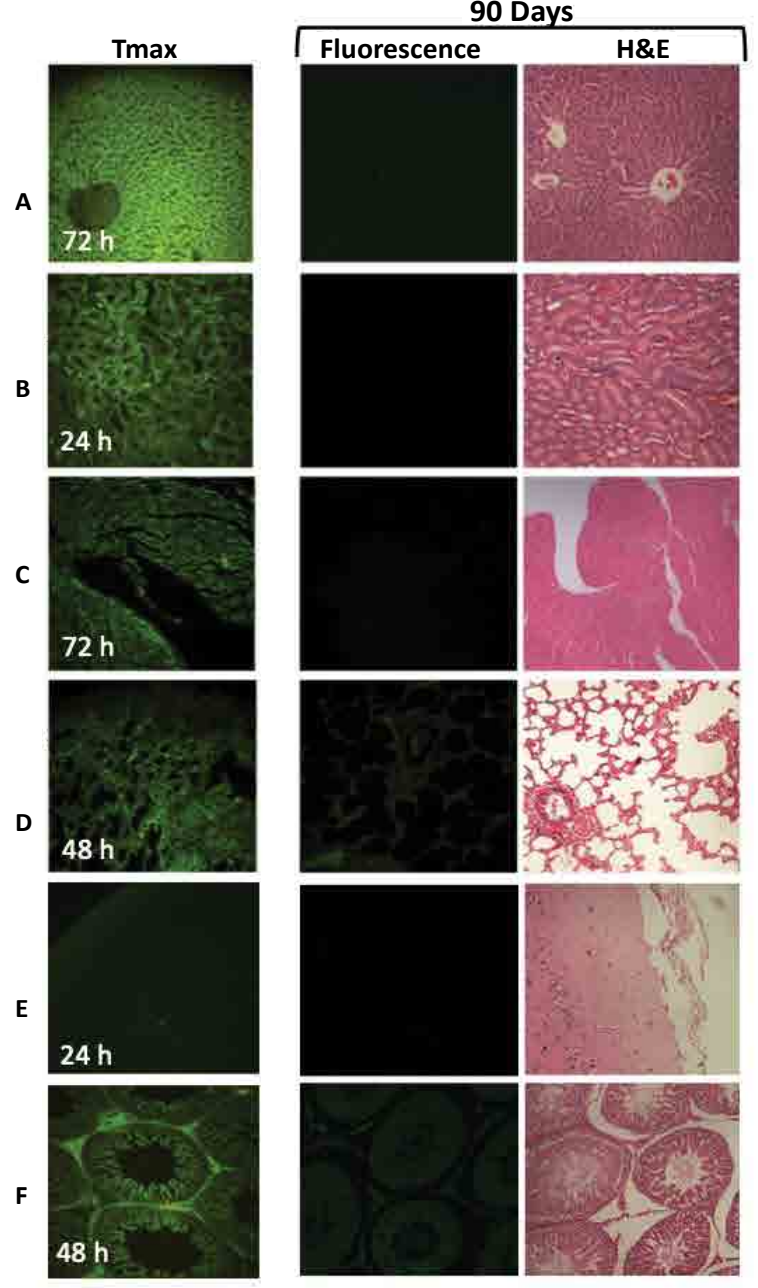

Fig. 2: Photomicrographs of distribution and localization of CS-DX nanoparticles in rat tissues

Distribution and localization of CS-DX nanoparticles in tissues from rats treated with a single dose of $100 \mu \mathrm{g} / \mathrm{kg}$ was studied using fluorescence microscopy images that showed the presence of nanoparticles through emission of green color. These images are from A. liver, B. kidney, C. heart, D. lung, E. brain and F. testis at the time of maximal concentration $\left(T_{\max }\right)$ and at $90 \mathrm{~d}$. All tissues were stained with $\mathrm{H}$ and $\mathrm{E}$. Magnification 20X
The present study assessed the disposition and biocompatibility of CS-DX nanoparticles administered as a single and multiple doses, respectively. There are currently very few reports on disposition and pharmacokinetics of nanomaterials. Given their size and reduced amounts in blood, this is sometimes easier to quantify in tissues ${ }^{[19,20]}$. Some researchers have developed theoretical mol rats and that their presence in the brain and testicles confirmed that these can cross barriers. Traces of nanomaterials have been detected in long-term studies after administering a single dose without producing toxicity. $\mathrm{Cr} 3+$-doped zinc gallate, $\mathrm{Zn}_{1.1} \mathrm{Ga}_{1.8} \mathrm{Sn}_{0.1} \quad \mathrm{O}_{4}: \mathrm{Cr}^{3+} \quad$ (ZGO) was administered intravenously over a period of $60 \mathrm{~d}$ and no toxicity was observed $^{[21]}$. Orally administered heparin-conjugated deoxycholic acid conjugates also showed no alterations in histology after $45 \mathrm{~d}^{[22]}$. Nanomaterial presence in some tissues has also been previously reported, including traces of iron-dopes silica nanoshells in lung and liver after $10 \mathrm{w}$ of their administration ${ }^{[23]}$. Carboxylated and pegylated few-layer graphene sheets were found within liver and spleen after 3 mo without producing toxicity ${ }^{[24]}$. These studies and the present study indicate nanomaterials have the capacity to remain for a long period of time in the organism without necessarily producing toxicity. This may be due to their inherent properties.

Modifications in glucose, triglyceride and ALP levels throughout the study were detected, suggesting possible liver damage. Most studies have focused on quantifying nanoparticle levels or identifying their distribution in tissues, while few have analysed their effects on physiological functions. One would expect that, lacking morphological alterations, the tissues

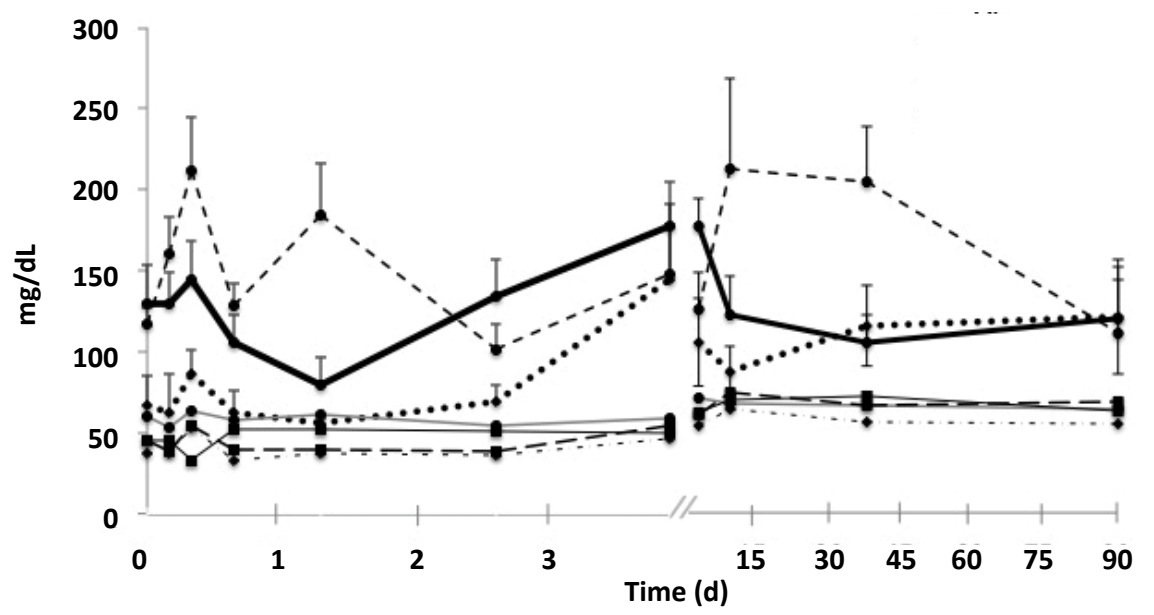

Fig. 3: Time-biochemical parameter profile after a dose of CS-DX

Time-biochemical parameter profiles after an intraperitoneal $100 \mu \mathrm{g} / \mathrm{kg}$ dose of CS-DX. Each point represents the mean \pm SD of 5 animals. (-) Glucose, (. . .) triglycerides, ( $(-)$ cholesterol, (--) AP, (-) AST, (-") ALT, (-"-) urea 


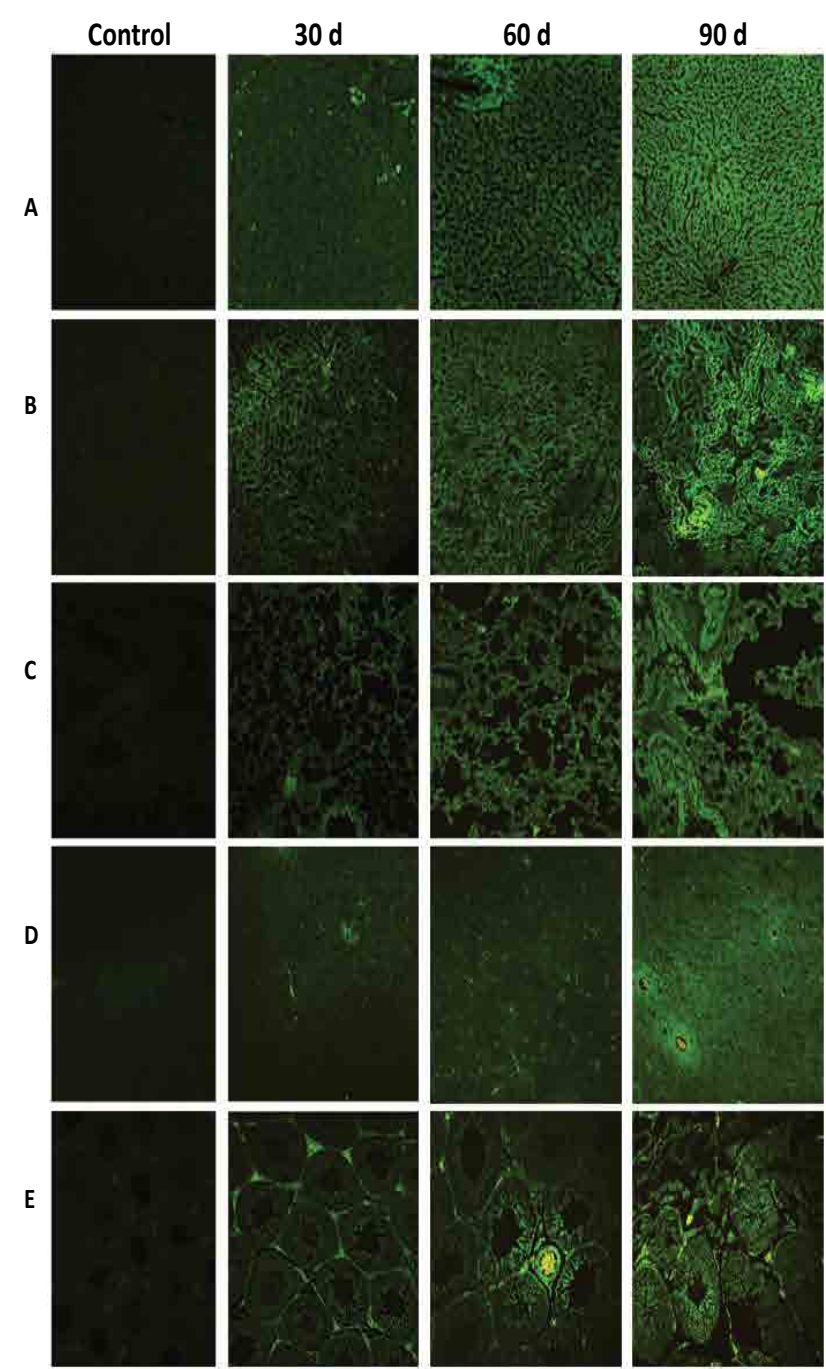

Fig 4: Photomicrographs of rat tissue sections with distribution and localization of CS-DX nanoparticles

Animals were treated daily with a dose of $100 \mu \mathrm{g} / \mathrm{kg}$ for 30 , 60 and $90 \mathrm{~d}$. Variations in the intensity of green fluorescence in each tissue are evident. Magnification 20X. (A) Liver, (B) kidney, (C) lung, (D) brain, (E) testis

would be functional. While the present study detected variations in biochemical parameters with in the initial $24 \mathrm{~h}$, it would seem that, after a long period of time, organs tend to adapt to the presence of nanomaterials and recover their functionality, an hypothesis confirmed by our biocompatibility studies.

Subchronic and chronic treatment with CS-DX nanoparticles demonstrated that these nanomaterials were well-tolerated. No functional or histological alterations were found in tissues from rats administered daily doses during $30 \mathrm{~d}$. At $60 \mathrm{~d}$, no morphological alterations could be seen in any analysed tissues even though there was an increase in ALP and urea levels, suggesting functional alterations in liver and kidney. There was significant toxicity data in animals treated daily for $90 \mathrm{~d}$, which showed degenerative changes in the testis and inflammation in lungs. Additionally, urea levels remained elevated at this time. Previous studies reported have shown that CS nanoparticles coated with polymers are able to cross biological barriers such as the hemato-encephalic and hemato-testicular ones ${ }^{[12,13]}$. Histologically speaking and given the observations made on rats, it seems the brain is not sensitive to these nanomaterials. However, the testicles appeared to be a particularly sensitive organ to toxic agents and drugs as well as nanomaterials. Nanomaterial toxic effects to testicular cells have been reported. Bara and Kaul reported that $\mathrm{ZnO}$ nanoparticles affected steroidogenesis and provoked alterations in phagosomes and lysosomes in Leydig cells ${ }^{[25]}$. Habas et al. found that silver-nanoparticles were able to enter sertoli cells and induce apoptosis and oxidative damage altering molecular pathways associated with that process ${ }^{[26]}$. It has also been reported that mice treated with carbonaceous nanoparticles showed changes in sperm viability, morphology and motility ${ }^{[27]}$. Nanomaterial-induced reproductive toxicity induced

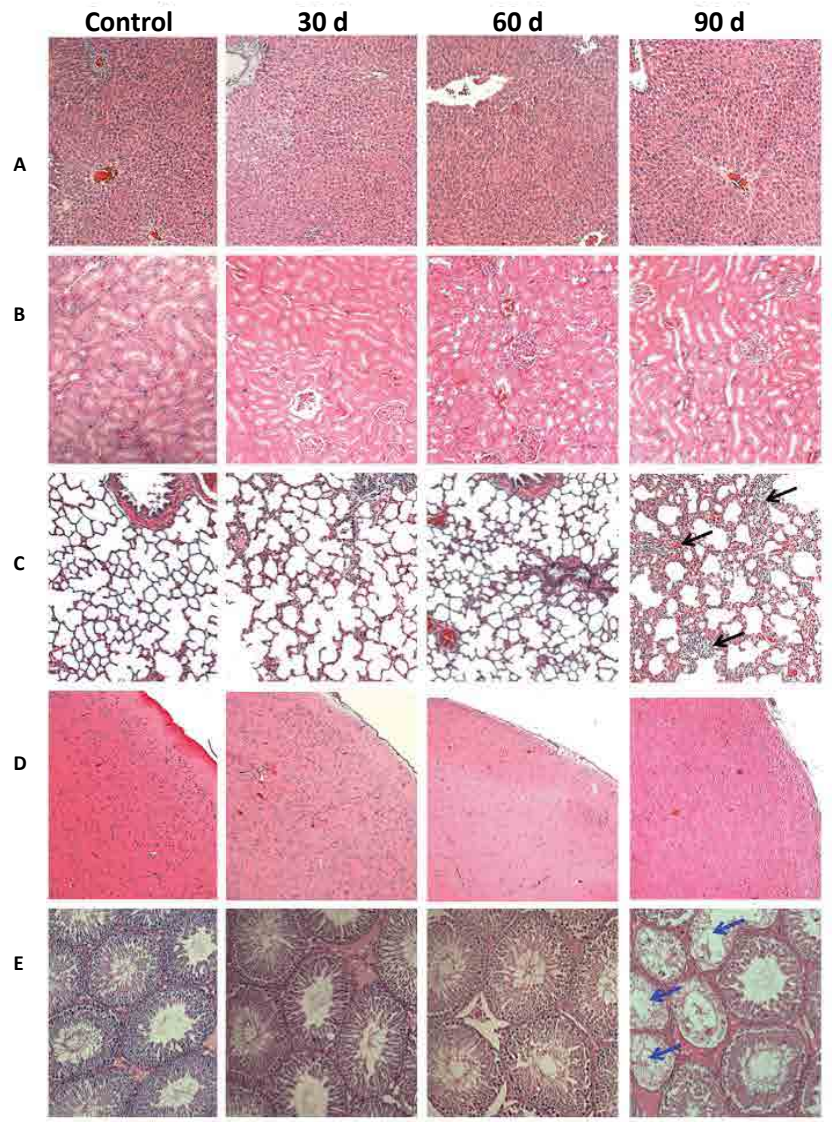

Fig. 5: Tissue histological sections from rats treated daily with CS-DX for 30, 60 and $90 \mathrm{~d}$

A chronic inflammatory process in lungs after $90 \mathrm{~d}$ of treatment was observed (black arrows). Atrophy and degenerative changes in testis after $90 \mathrm{~d}$ were observed (blue arrows). Tissue samples were stained with $H$ and $E$. Margnification 20X. (A) Liver, (B) kidney, (C) lung, (D) brain, (E) testis 
TABLE 2: EFFECT OF CS-DX NANOPARTICLES ON BIOCHEMICAL PARAMETERS IN RATS TREATED DAILY FOR 30, 60 AND 90 DAYS ( $n=6)$

\begin{tabular}{lcccc}
\hline Parameter & Control & 30 days & 60 days & 90 days \\
\hline Glucose & $140.2 \pm 19.4$ & $120.5 \pm 36.1$ & $152.0 \pm 43.3$ & $159.9 \pm 19.4$ \\
Triglycerides & $60.8 \pm 13.7$ & $112.3 \pm 51.7$ & $122.4 \pm 34.4$ & $187.0 \pm 15.5$ \\
Cholesterol & $54.9 \pm 8.9$ & $59.4 \pm 12.9$ & $58.7 \pm 3.3$ & $64.9 \pm 10.3$ \\
ALT & $54.3 \pm 8.6$ & $54.5 \pm 8.9$ & $74.9 \pm 25$ & $57.5 \pm 9.7$ \\
AST & $160.2 \pm 26$ & $168.3 \pm 20.1$ & $146.5 \pm 40.9$ & $176.1 \pm 29.0$ \\
AP & $121.6 \pm 33.7$ & $156.9 \pm 13$ & $210 \pm 31.4^{* \# \#}$ & $113.8 \pm 23.8$ \\
Urea & $39.6 \pm 8.4$ & $35.8 \pm 6.6$ & $55.9 \pm 8.3^{* \#}$ & $50.8 \pm 2.0^{\#}$ \\
Creatinine & $0.6 \pm 0.1$ & $0.5 \pm 0.1$ & $0.4 \pm 0.1$ & $0.7 \pm 0.04$ \\
Uric Acid & $5.2 \pm 1.8$ & $5.6 \pm 1.7$ & $10.6 \pm 5.4$ & $10.5 \pm 3.4$ \\
\hline
\end{tabular}

Each value represents the mean $\pm S D$. * $P<0.05$ compared with control group; ${ }^{\#} p<0.05$ compared with $30 \mathrm{~d}$ group; ${ }^{* *} \mathrm{p}<0.05$ compared with $60 \mathrm{~d}$ group; and ${ }^{\text {\& }} \mathrm{p}<0.05$ compared with $90 \mathrm{~d}$ group

by is now a topic of interest for several researchers. Recently, several reports have evidenced nanomaterial toxicity in different reproductive organs ${ }^{[28-32]}$.

Toxicity induced by nanomaterials administered not by airway has been previously reported. Wang et al. reported an inflammatory process in the lungs after oral administration of halloysite nanotubes to mice, suggesting nanomaterials might accumulate in the lungs, and induce fibrosis ${ }^{[33]}$. On the other hand, other studies have revealed many histological changes in the lung, cellular infiltration and thrombosis in fetuses following an intravenous injection to pregnant rats $^{[34]}$, follicular atresia in female mice ${ }^{[35]}$, and malformation and injury to different organs ${ }^{[36]}$. These results and others suggest that, regardless of the route of administration, lung tissue captures and retains nanoparticles, thus suffering the concomitant toxic effects.

Although the present study revealed several biochemical alterations during the first hour after the administration of a single dose of CS-DX nanoparticles and some of these remained throughout the $90 \mathrm{~d}$, it is striking that, after the administration of multiple doses, the functionality of the organs showed no deterioration. On the contrary, some of the alterations were reversed. As previously indicated, it seems that, after administration, the organs adapt to the presence of nanoparticles and these remain there without producing toxicity in the tissues.

It has been mentioned that cadmium induces several toxic effects to cells and can affect DNA, RNA and protein $\mathrm{s}^{[37-39]}$. Even exposure to cadmium-containing nanoparticles could lead to disturbances in cellular homeostatic mechanisms ${ }^{[40-42]}$. Present results demonstrated that CS-DX nanoparticles did not cause severe damage to rats receiving nanoparticles, nor did they produce death. The findings of this study suggested that CS nanoparticles protected with dextrin control toxicity related to cadmium leakage.

It was observed that CS-DX nanoparticles have a wide distribution and a very long MRT without producing significant toxicity. The multi-dose study showed these nanoparticles were biocompatible and only produced selective toxicity after administration for very long time periods. Due to the high intensity of fluorescence emitted by the CS-DX nanoparticles, it was possible to clearly visualizes the tissue morphology; therefore these have the potential to be used in bioimaging in diagnostic and treatment activities. Although nanoparticles have shown to have selective toxicity further research is needed to ensure nanoparticles are safely and efficiently used in medicine.

\section{Acknowledgements:}

The authors would like to thank to Mariana Ortega for her technical assistance. Gerardo González wishes thank CONACYT under grant 254414.

\section{Conflict of interest:}

The author's report no declaration of interest, financial or otherwise regarding this project.

\section{REFERENCES}

1. Thiruvengadam M, Rajakumar G, Chung IM. Nanotechnology: current uses and future applications in the food industry. 3 Biotech 2018;8(1):74.

2. Fennell TR, Mortensen NP, Black SR, Snyder RW, Levine $\mathrm{KE}$, Poitras E, et al. Disposition of intravenously or orally administered silver nanoparticles in pregnant rats and the effect on the biochemical profile in urine. J Appl Toxicol 2017;37(5):530-44.

3. Lin X, Gao R, Zhang Y, Qi N, Zhang Y, Zhang K, et al. Lipid nanoparticles for chemotherapeutic applications: strategies to improve anticancer efficacy. Expert Opin Drug Deliv 2012;9(7):767-81.

4. Liang $\mathrm{X}$, Wang $\mathrm{H}$, Grice JE, Li L, Liu X, Xu ZP, et 
al. Physiologically Based Pharmacokinetic Model for Long-Circulating Inorganic Nanoparticles. Nano Lett 2016;16(2):939-45.

5. Yoshikawa $T$, Nabeshi $H$, Yoshioka Y. Evaluation of biological influence of nano-materials using toxicokinetic and toxicoproteomic approach. Yakugaku Zasshi 2008;128(12):1715-25.

6. Durišová MA. Physiological view and structures of mean residence times. Gen Physiol Biophys 2014;33;75-80.

7. Kettiger H, Schipanski A, Wick P, Huwyler J. Engineered nanomaterial uptake and tissue distribution: from cell to organism. Int J Nanomedicine 2013;8:3255-6.

8. Hara E, Makino A, Kurihara K, Yamamoto F, Ozeki E, Kimura S. Pharmacokinetic change of nanoparticulate formulation "Lactosome" on multiple administrations. Int Immunopharmacol 2012;14(3):261-6.

9. Kaminskas LM, Boyd BJ, Porter CJ. Dendrimer pharmacokinetics: the effect of size, structure and surface characteristics on ADME properties. Nanomedicine 2011;6(6):1063-84.

10. Song X, Zhao X, Zhou Y, Li S, Ma Q. Pharmacokinetics and disposition of various drug loaded biodegradable poly(lactide-co-glycolide) (PLGA) nanoparticles. Curr Drug Metab 2010;11(10):859-69.

11. Qi J, LuY,WuW.Absorption, disposition and pharmacokinetics of solid lipid nanoparticles. Curr Drug Metab 2012;13(4):41828.

12. Rodríguez-Fragoso $\mathrm{P}$, Reyes-Esparza J, León-Buitimea A, Rodríguez-Fragoso L. Synthesis, characterization and toxicological evaluation of maltodextrin capped cadmium sulfide nanoparticles in human cell lines and chicken embryos. J Nanobiotechnolgy 2012;10;47:1-11.

13. Reyes-Esparza J, Martínez-Mena A, Gutiérrez-Sancha I, Rodriguez-Fragoso P. González de la Cruz G, Mondragón $\mathrm{R}$, et al. Synthesis, characterization and biocompatibility of cadmium sulfide nanoparticles capped with dextrin for in vivo and in vitro imaging application. J Nanobiotechnology 2015;13:2-14.

14. Gómez-Cansino R, Reyes-Esparza JA, Rodríguez-Fragoso P, González de la Cruz G, Rodríguez-Fragoso L. Long Exposure to CdS-Dextrin Nanoparticles Induces an Immunomodulatory and Anti-Inflammatory Effect in Rats. J Mater Sci Nanotech 2017;5(1):2-10.

15. National Research Council (US), Guide for the Care and Use of Laboratory Animals. 8th ed. National Academies Press, Washington (DC), 2011. Available from: https:/grants.nih. gov/grants/olaw/Guide-for-the-care-and-use-of-laboratoryanimals.pdf.

16. Zheng H. Intravenous infusion. In: Shargel L, Yu ABC, editors. Applied Biopharmaceutics \& Pharmacokinetics. 1st ed. New York. McGraw-Hill; 2012. p. 245-312.

17. Jambhekar SS, Breen PJ. Basic Pharmacokinetics. Greyslake (IL): Pharmaceutical Press; 2009.

18. Hacker M, Bachmann K, Messer W. Pharmacokinetics modeling. Pharmacology principles and practice. California: Academic Press; 2009.

19. Choi SJ, Choy JH. Biokinetics of zinc oxide nanoparticles: toxicokinetics, biological fates, and protein interaction. Int J Nanomedicine 2014;9(Suppl 2):261-9.

20. Saitoh Y, Terada N, Saitoh S, Ohno N, Jin T, Ohno S. Histochemical analyses and quantum dot imaging of microvascular blood flow with pulmonary edema in living mouse lungs by "in vivo cryotechnique". Histochem Cell Bio 2012;137:137-51.

21. Sun X, Shi J, Fu X, Yang Y, Zhang H. Long term in vivo biodistribution and toxicity study of functionalized nearinfrared persistent luminiscence nanoparticles. Sci Rep 2018;8:10595.

22. Khatun Z, Nurumnnabi M, Lee DY, Kim YJ, Byun Y, Cho $\mathrm{KJ}$, et al. Optical imagin, biodistribution and toxicity of orally administered quantum dots loaded heparin-deoxycholic acid. Macromol Res 2015;23:686-95.

23. Mendez N, Liberman A, Corbeil J, Barback C, Viveros R, Wang $\mathrm{J}$, et al. Assessment of in vivo systemic toxicity and biodistribution of iron-doped silica nanoshells. Nanomedicine 2017;13(3):933-42.

24. Sasidharan A, Swaroop S, Koduri CK, Girish C, Chandran $\mathrm{P}$, Panchakarla LS, et al. Comparative in vivo toxicity, organ biodistribution and immune response of pristine, carboxilated and PEGylated few-layer graphene sheets in Swis albino mice: a three month study. Carbon 2015;95:511-24.

25. Bara N, Kaul G. Enhanced steroidogenic and altered antioxidant response by $\mathrm{ZnO}$ nanoparticles in mouse testis Leydig cells. Toxicol Ind Health 2018;34(8):571-88.

26. Habas K, Brinkworth MH, Anderson D. Silver nanoparticlemediated cellular responses in isolated primary Sertoli cells in vitro. Food Chem Toxicol 2018;116(Pt B):182-8.

27. Skovmand A, Jacobsen Lauvås A, Christensen P, Vogel U, Sørig Hougaard K, Goericke-Pesch S. Pulmonary exposure to carbonaceous nanomaterials and sperm quality. Part Fibre Toxicol 2018;15(1):10.

28. Mao Z, Yao M, Xu B, Ji X, Jiang H, Han X, et al. Cytoskeletons of Two Reproductive Germ Cell Lines Response Differently to Titanium Dioxide Nanoparticles Mediating Vary Reproductive Toxicity. J Biomed Nanotechnol 2017;13(4):409-16.

29. Adebayo OA, Akinloye O, Adaramoye OA. Cerium oxide nanoparticle elicits oxidative stress, endocrine imbalance and lowers sperm characteristics in testes of balb/c mice. Andrologia 2018; 50(3):12920.

30. Moshari S, Nejati V, Najafi G, Razi M. Insight into curcumin nanomicelle-induced derangements in male reproduction potential: An experimental study. Andrologia 2018;50(2):12842.

31. Miura N, Ohtani K, Hasegawa T, Yoshioka H, Hwang GW. High sensitivity of testicular function to titanium nanoparticles. J Toxicol Sci 2017;42(3):359-66.

32. Almansour M, Jarrar Q, Battah A, Jarrar B. Histomorphometric Alterations Induced in the Testicular Tissues by Variable Sizes of Silver Nanoparticles. J Reprod Med 2017;62(5-6):317-23.

33. Wang X, Gong J, Rong R, Gui Z, Hu T, Xu X. Halloysite Nanotubes-Induced Al Accumulation and Fibrotic Response in Lung of Mice after 30-Day Repeated Oral Administration. J Agric Food Chem 2018;66(11):2925-33.

34. Lee J, Yu WJ, Song J, Sung C, Jeong EJ, Han JS, et al. Developmental toxicity of intravenously injected zinc oxide nanoparticles in rats. Arch Pharm Res 2016;39(12):1682-92.

35. Liu J, Yang M, Jing L, Ren L, Wei J, Zhang J, et al. Silica nanoparticle exposure inducing granulosa cell apoptosis and follicular atresia in female Balb/c mice. Environ Sci Pollut Res Int 2018;25(4):3423-34.

36. Zhang Y, Wu J, Feng X, Wang R, Chen A, Shao L. Current understanding of the toxicological risk posed to the fetus 
following maternal exposure to nanoparticles. Expert Opin Drug Metab Toxicol 2017;13(12):1251-63.

37. Li KG, Chen JT, Bai SS, Wen X, Song SY, Yu Q, et al. Intracellular oxidative stress and cadmium ions release induce cytotoxicity of unmodified cadmium sulfide quantum dots. Toxicol Vitro 2009;23:1007-13.

38. Ospondpant D, Phuagkhaopong S, Suknuntha K, Sangpairoj $\mathrm{K}$, Kasemsuk T, Srimaroeng $\mathrm{C}$, et al. Cadmium induces apoptotic program imbalance and cell cycle inhibitor expression in cultured human astrocytes. Environ Toxicol Pharmacol 2019;65:53-9.

39. Adebambo OA, Shea D, Fry RC. Cadmium disrupts signaling of the hypoxia-inducible (HIF) and transforming growth factor (TGF- $\beta$ ) pathways in placental JEG-3 trophoblast cells via reactive oxygen species. Toxicol Appl Pharmacol 2018;342:108-15.

40. Naderi S, Zare H, Taghavinia N, Irajizad A, Aghaei M, Panjehpour M. Cadmium telluride quantum dots induce apoptosis in human breast cancer cell lines. Toxicol Ind Health 2018;34(5):339-52.

41. Liu J, Hu R, Liu J, Zhang B, Wang Y, Liu X, et al. Cytotoxicity assessment of functionalized $\mathrm{CdSe}, \mathrm{CdTe}$ and $\mathrm{InP}$ quantum dots in two human cancer cell models. Mater Sci Eng C Mater Biol Appl 2015;57:222-31.

42. Nan C, Yao H, Yuanyuan S, Xiaoming L, Qing H, Haifeng $\mathrm{W}$, et al. The cytotoxicity of cadmium-based quantum dots. Biomaterials 2012;33:1238-44. 